\title{
Peta 3D Desa Muncan dengan Augmented Reality Berbasis Marker
}

\author{
Lalu Atasaldi ${ }^{1}$, Saeful Hamdi ${ }^{2}$, Ichwan Purwata ${ }^{3}$ \\ 1,2,3 STMIK Lombok, Lombok Tengah, Indonesia \\ 1ataq48@gmail.com, ${ }^{2}$ saefulhamdi@gmail.com, ${ }^{3 *}$ ichwanpurwata2017@gmail.com \\ Email: ${ }^{1)}$ ataq48@gmail.com
}

\begin{abstract}
Abstrak-Augmented reality adalah teknologi yang menggabungkan benda maya 2D ataupun 3D ke dalam lingkungan nyata. Augmented reality dapat digunakan dalam berbagai bidang, salah satunya digunakan untuk pengenalan suatu wilayah dengan bentuk 3D. Desa Muncan memiliki luas wilayah $\pm 325,180 \mathrm{ha} / \mathrm{m} 2$, mengenai luas dan batas wilayah Desa Muncan, penduduk Desa Muncan kesulitan dalam menemukan rumah kepala dusun, sekolah, masjid ataupun potensi yang ada di dusun lain. Begitu juga dengan penduduk luar Desa Muncan yang akan mencari suatu produk di Desa Muncan. Ada juga tempat-tempat sumber perekonomian, wisata dan budaya di Desa Muncan yang lokasinya jarang diketahui oleh penduduk Desa Muncan. Dalam hal tersebut dibutuhkan media informasi yang dapat memberikan petunjuk serta menampilkan tempat-tempat strategis dan potensi yang ada pada masing-masing dusun yang ada di Desa Muncan dalam bentuk Peta 3D dengan teknologi augmented reality dengan tujuan terlihat lebih nyata dan dapat diakses dimana saja melalui smartphone.
\end{abstract}

Kata Kunci: Peta 3D Desa Muncan, Augmented Reality, MDLC, Android, Marker

\begin{abstract}
Augmented reality is a technology that combines 2D or 3D virtual objects into a real environment. Augmented Reality can be used in various fields, one of which is used for the introduction of an area with 3D forms. Muncan Village has an area of $\pm 325,180 \mathrm{ha} / \mathrm{m} 2$, regarding the area and boundaries of Muncan Village, the residents of Muncan Village have difficulty finding houses for the hamlet head, schools, mosques or the potential in other hamlets. Likewise with residents outside Muncan Village who will look for a product in Muncan Village. There are also places of economic, tourism and cultural sources in Muncan Village whose location is rarely the residents of Muncan Village themselves know their location. In this case, information media is needed that can provide instructions and display strategic places and the potential that exists in each hamlet in Muncan Village in the form of a 3D Map with Augmented Reality technology with the aim of making it look more real and can be accessed anywhere via a smartphone.
\end{abstract}

Keywords: Muncan Village 3D Map, Augmented Reality, MDLC, Android, Marker

\section{PENDAHULUAN}

Desa Muncan merupakan salah satu desa yang terletak di Kecamatan Kopang Kabupaten Lombok Tengah, Nusa Tenggara Barat. Menurut Profil Desa Muncan yang diisi oleh Mastur (Pemerintah Desa) pada tahun 2017, Desa Muncan memiliki luas wilayah $\pm 325,180 \mathrm{ha} / \mathrm{m} 2$ dan dibagi menjadi 10 dusun antara lain Dusun Muncan I, Dusun Muncan II, Dusun Muncan III, Dusun Muncan IV, Dusun Montong Batu I, Dusun Montong Batu II, Dusun Talun, Dusun Prantap, Dusun Lingkung dan Dusun Sumbek [1].

Karena luas wilayah dan banyaknya dusun yang ada, penduduk Desa Muncan kesulitan dalam menemukan rumah kepala dusun, sekolah, masjid ataupun potensi yang ada di dusun lain. Begitu juga dengan penduduk luar Desa Muncan yang akan mencari suatu produk di Desa Muncan. Ada juga tempat-tempat sumber perekonomian, wisata dan budaya di Desa Muncan yang lokasinya jarang penduduk Desa Muncan sendiri mengetahui lokasinya. Dalam hal tersebut dibutuhkan media informasi yang dapat memberikan petunjuk serta menampilkan tempat-tempat strategis dan potensi yang ada dimasing-masing dusun yang ada di Desa Muncan. Dari permaslaah tersebut penulis membuat tugas akhir dengan judul "Peta 3D Desa Muncan dengan teknologi Augmented Reality berbasis Marker" dengan alur sistem dari penggunaan marker, yaitu aplikasi AR akan mengakses kamera perangkat, kemudian sistem akan mendeteksi marker melalui kamera, lalu menampilkan objek virtual di atas marker tersebut pada layar perangkat dengan tujuan terlihat lebih nyata dan dapat diakses dimana saja melalui smartphone [2].

Aplikasi adalah alat terapan yang berfungsi secara khusus dan terpadu sesuai kemampuan yang dimilikinya. Aplikasi merupakan suatu perangkat komputer yang siap pakai bagi pengguna / user [3].

Peta dalam bahasa inggris lazim disebut istilah map, yang berasal dari bahasa Yunani mappa yang berarti taplak meja. Secara umum peta dapat diartikan sebagai gambaran seluruh atau sebagian permukaan bumi dalam bidang datar yang diperkecil dengan skala tertentu dan dilengkapi dengan simbol-simbol. Ilmu yang mempelajari tentang peta disebut Kartografi dan orang yang ahli dalam membuat peta disebut Kartografer [4] 
Augmented reality adalah adalah teknologi yang menggabungkan benda maya dua dimensi dan ataupun tiga dimensi ke dalam sebuah lingkungan nyata tiga dimensi lalu memproyeksikan benda-benda maya tersebut dalam waktu nyata [5].

Metode yang memanfaatkan marker (penanda) berupa ilustrasi hitam putih berbentuk persegi atau ilustrasi gambar dengan warna dan bentuk tertentu. Secara umum, metode marker membutuhkan beberapa hal dalam pengolahannya, seperti perangkat komputer atau mobile yang dilengkapi dengan kamera dan sensor pendukung $A R$, aplikasi $A R$ dan marker. Alur sistemnya, yaitu aplikasi $A R$ akan mengakses kamera perangkat, kemudian sistem akan mendeteksi marker melalui kamera, lalu menampilkan objek virtual di atas marker tersebut pada layar perangkat [6].

Unity salah satu game engine yang mudah digunakan, hanya membuat objek dan diberikan fungsi untuk menjalankan objek tersebut. Dalam setiap objek mempunyai variabel, variabel inilah yang harus dimengerti supaya dapat membuat game yang berkualitas. Berikut adalah bagian-bagian dalam unity: (1) asset yang adalah tempat penyimpanan dalam unity yang menyimpan suara, gambar, video, dan tekstur, (2) scenes adalah area yang berisikan konten-konten dalam game, seperti membuat sebuah level, membuat menu, tampilan tunggu, dan sebagainya, (3) game objects adalah barang yang ada di dalam assets yang dipindah ke dalam scenes, yang dapat digerakkan, diatur ukurannya dan diatur rotasiny, (4) components adalah reaksi baru, bagi objek seperti collision, memunculkan partikel, dan sebagainya, (5) script, yang dapat digunakan dalam unity ada tiga, yaitu Javascript, C\# dan BOO, (6) prefabs adalah tempat untuk menyimpan satu jenis game objects, sehingga mudah untuk diperbanyak [7].

Vuforia SDK merupakan Software Development Kit berbasis AR yang menggunakan layar perangkat mobile sebagai "lensa ajaib" atau kaca untuk melihat kedalam dunia augmented dimana dunia nyata dan virtual muncul berdampingan [8].

Blender adalah rangkaian pembuatan 3D sumber terbuka dan gratis. Blender mendukung keseluruhan pipa 3D-pemodelan, pemasangan, animasi, simulasi, rendering, pengkomposisian dan pelacakan gerak, pengeditan video, dan pipa animasi 2D [9].

MDLC (Multimedia Development Life Cycleversi) terdiri dari enam tahapan yaitu concept, design, material collecting, assembly, testing dan distribution [10].

\section{METODE PENELITIAN}

Dalam penelitian yang dilakukan, digunakan beberapa metode penelitian, berikut tahap-tahap penelitian yang dilakukan oleh peneliti :

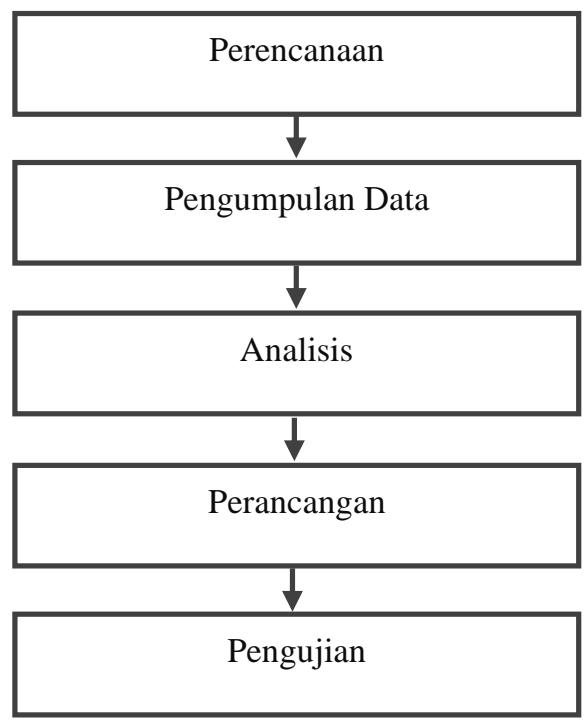

Gambar 1. Metode Penelitian

\subsection{Perencanaan}

Tahap awal yang dilakukan peneliti adalah tahap perencanaan, pada tahap perencanaan, peneliti membuat jadwal dan tempat penelitian, hal tersebut bertujuan agar penelitian dapat dilaksanakan dengan baik dan lebih terstruktur.

\subsection{Pengumpulan Data}

Pengumpulan data yang digunakan peneliti ada tiga cara, yaitu : 
a. Studi Pustaka

Peneliti mempelajari, meneliti dan menelaah berbagai literatur dari berbagai sumber seperti buku, jurnal ilmiah, situs internet dan bacaan lainnya yang berkaitan dengan penelitian yang dilakukan.

b. Wawancara

Peneliti melakukan tanya jawab lansung kepada narasumber. Diantaranya kepala Desa Muncan, kepala dusun, tokoh masyarakat dan narasumber lainnya.

c. Observasi

Observasi dilakukan untuk memperoleh data dan informasi yang akurat tentang penelitian yang dilakukan dengan cara melihat secara langsung pada wilayah Desa Muncan.

\subsection{Analisis}

Metode analisis yang digunakan adalah SWOT (Strengths, Weaknesses, Opportunities, Threats). Metode SWOT mengatur kekuatan, kelemahan, peluang, dan ancaman utama ke dalam daftar yang terorganisir dan biasanya disajikan dalam bilah kisi-kisi yang sederhana.

\subsection{Perancangan}

Dalam perancangan aplikasi, peneliti menggunakan metode Multimedia Development Life Cycle (MDLC). MDLC terdiri dari 6 tahapan, yaitu concept, design, material collecting, assembly, testing dan distribution.

\subsection{Pengujian}

Metode pengujian yang digunakan peneliti untuk mengetahui hasil uji dari aplikasi yang telah dibuat. Metode pengujian yang dipilih oleh penguji adalah Blackbox testing.

\section{HASIL DAN PEMBAHASAN}

\subsection{Flowchart Aplikasi}

Flowchart aplikasi bertujuan untuk menggambarkan alur proses dari aplikasi yang telah dibuat oleh peneliti.

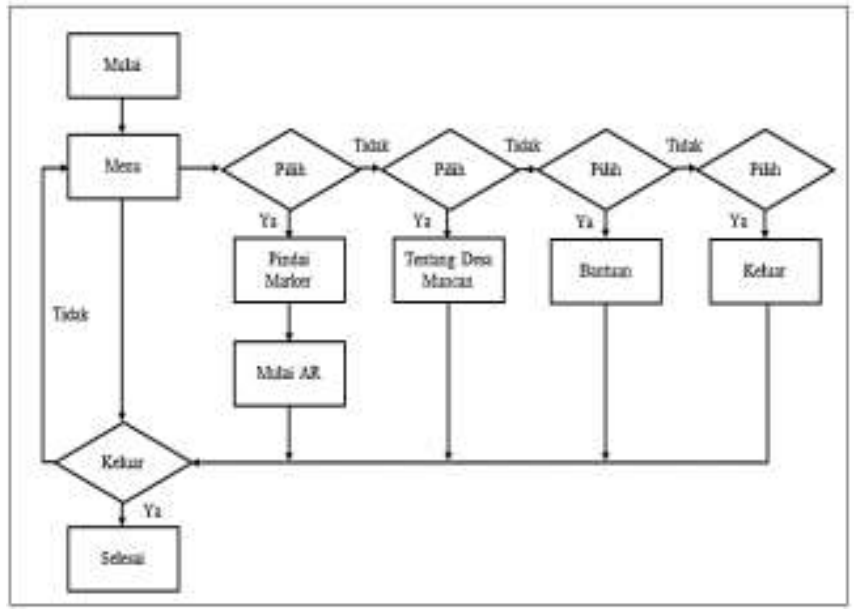

Gambar 2. Flowchart aplikasi peta 3D Desa Muncan

\subsection{Implementasi}

\subsubsection{Desain Peta 3D Desa Muncan}

Berikut bentuk peta 3D Desa Muncan: 


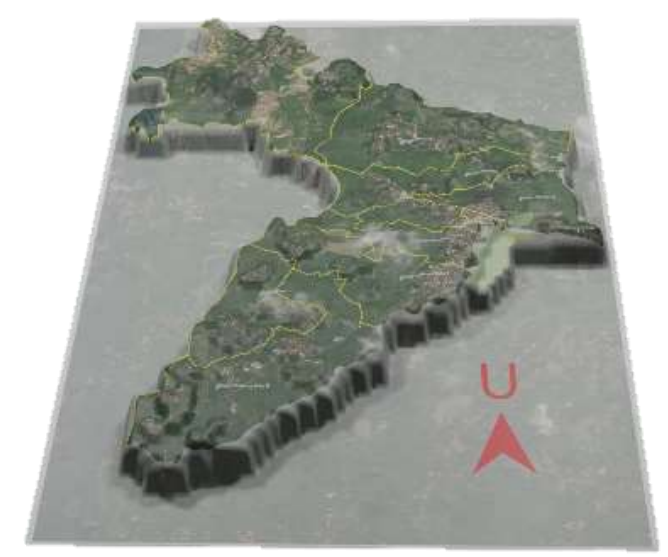

Gambar 2. Peta 3D Desa Muncan

\subsubsection{Desain Marker}

Berikut beberapa desain marker yang digunakan di beberapa wilayah Desa Muncan :

a. Marker wilayah utara Desa Muncan

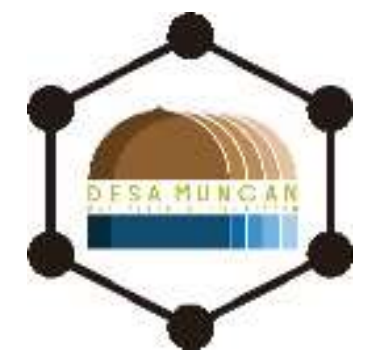

Gambar 3. Marker wilayah utara Desa Muncan

b. Marker wilayah tengah Desa Muncan

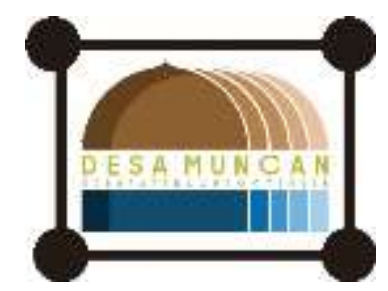

Gambar 4. Marker wilayah tengah Desa Muncan

c. Marker wilayah selatan Desa Muncan

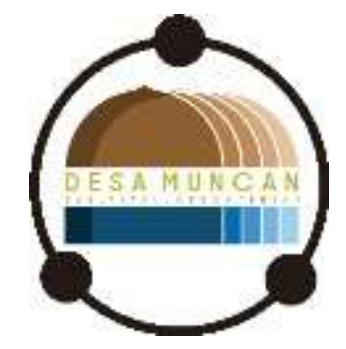

Gambar 5. Marker wilayah selatan Desa Muncan

\subsubsection{Interface Aplikasi}

a. Halaman Beranda

Halaman utama dari aplikasi peta 3D Desa Muncan dengan $A R$ berbasis marker. Pada halam beranda terdapat beberapa menu antara lain menu pindai marker, menu tentang Desa Muncan, menu bantuan dan tombol exit. 


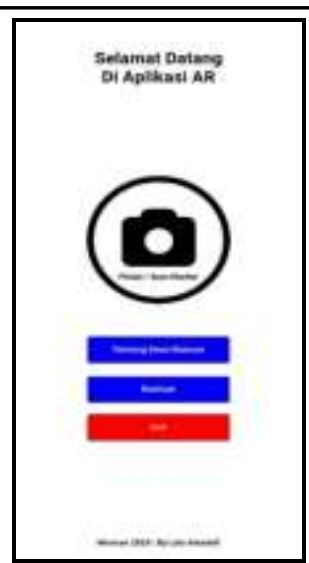

\section{Gambar 6. Interface Halaman Beranda}

a. Halaman Scan/Pindai marker

Menampilkan proses pemindaian marker tersebut menggunakan teknologi augmented reality. Proses tersebut dimulai saat kamera terbuka dan akan mendeteksi marker. Jika merker terdeteksi akan terlihat peta 3D Desa, jika marker tidak terdeteksi maka kamera akan terus mencari marker sampai pengguna memilih tombol batal untuk mengakhiri proses pindai marker.

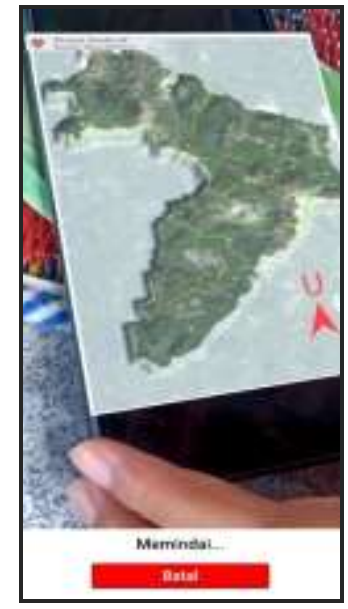

Gambar 7. Interface halaman scan/pindai marker

b. Halaman Tentang Desa Muncan

halaman yang berisikan deskripsi singkat tentang Desa Muncan. Kemudian ada simbol panah kekiri untuk digunakan kembali ke halaman beranda.

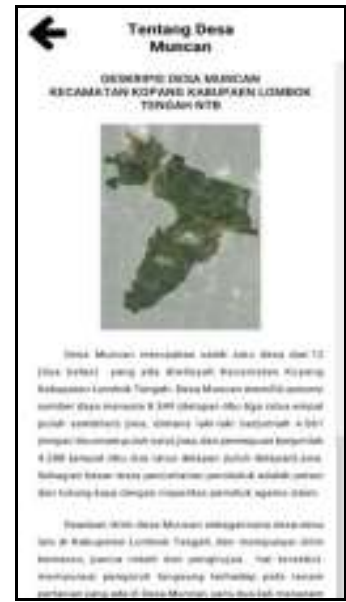

Gambar 8. Interface halaman Tentang Desa Muncan 
c. Halaman Bantuan

Halaman bantuan berfungsi sebagai halaman yang memberikan informasi mengenai cara menjalankan aplikasi dan terdapat simbol panah ke kiri untuk digunakan kembali ke halaman beranda.

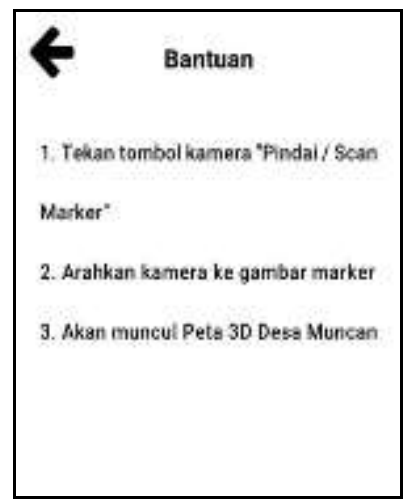

Gambar 9. Interface halaman Bantuan

\subsubsection{Database}

Penyimpanan marker berupa logo Desa Muncan disimpan pada website vuforia.

\section{a. License Manager}

License manager berfungsi sebagai tempat mendaftarkan database yang akan dibuat sebagai tempat mendapatkan kode license key untuk mensinkronkan marker dengan object yang dibuat. Proses tersebut hanya dilakukan saat pembuatan aplikasi augmented reality, ketika aplikasi sudah jadi dan berhasil dijalankan, proses sinkronisasi marker tersebut tidak perlu dilakukan lagi oleh pengguna aplikasi.

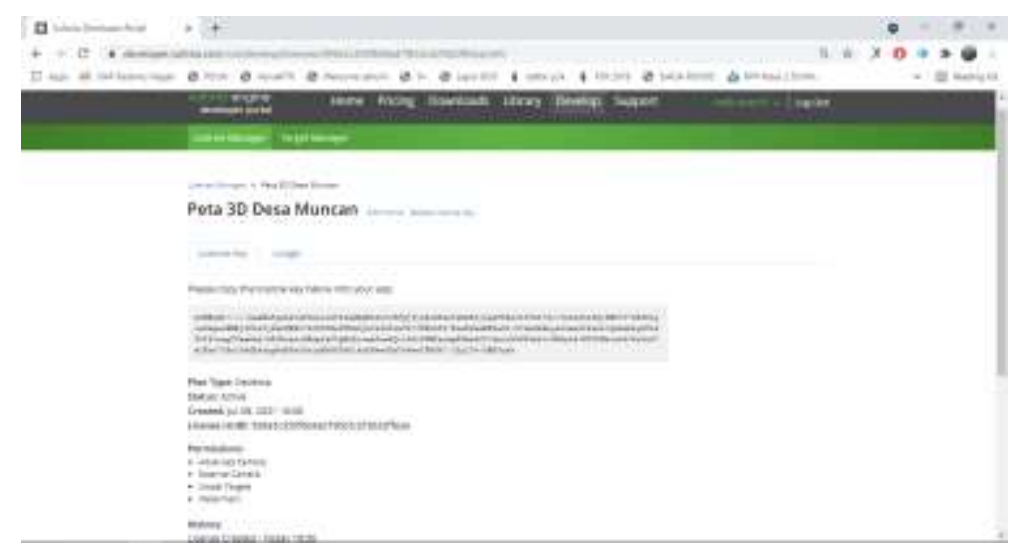

Gambar 10. License manager peta 3D Desa Muncan

b. Target Manager

Target manager berfungsi sebagai tabel tempat menyimpan marker atau penanda yang akan digunakan. Adapun terdapat tiga buah marker dengan garis tepi berbeda berdasarkan lokasi marker ditempatkan, yaitu marker Dusun Sumbek untuk wilayah utara Desa Muncan, kemudian marker kantor Desa Muncan sebagai wilayah tengah yang Desa Duncan dan marker Dusun Montong Batu 2 sebagai marker penanda di wilayah Muncan bagian selatan. 


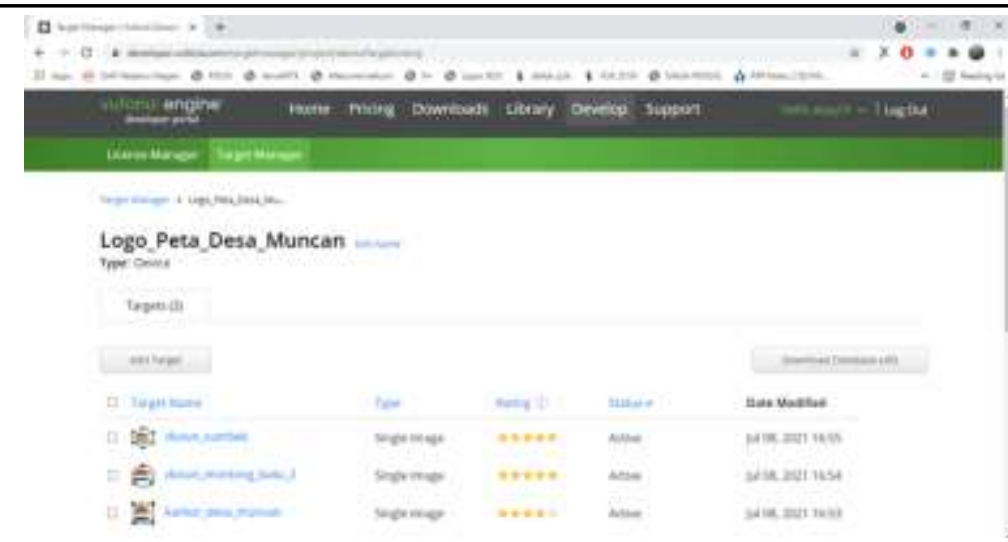

Gambar 11. Target manager peta 3D Desa Muncan

\subsubsection{Pengujian}

Tabel 1. Pegujian Blackbox testing

\begin{tabular}{lllll}
\hline No & Skenario & Test Case & Harapan & Hasil \\
\hline 1 & Icon Aplikasi & Icon Aplikasi & Icon dipilih untuk membuka aplikasi & Berhasil \\
\hline 2 & Tombol & $\begin{array}{l}\text { Tombol Pindai/scan } \\
\text { marker } \\
\text { Tombol Tentang } \\
\text { Desa Muncan } \\
\text { Tombol Bantuan } \\
\text { Tombol } \text { Exit }\end{array}$ & Tombol dapat berfungsi dengan tepat & Berhasil \\
& & & \\
& & $\begin{array}{l}\text { Mengukur } \\
\text { kemiringan kamera } \\
\text { dengan } \text { marker }\end{array}$ & $\begin{array}{l}\text { Kamera dapat mendeteksi } \text { marker } \text { dengan } \\
\text { kemiringan } 0^{\circ} \text { sampai } 75^{\circ}\end{array}$ & Berhasil \\
\hline 3 & Kemiringan & & \\
kamera & Kontras marker & $\begin{array}{l}\text { Mengukur kontras } \\
\text { marker }\end{array}$ & $\begin{array}{l}\text { Marker } \text { dapat terdeteksi dengan keadaan kontras } \\
\text { kurang } 0 \text { - } 90 \%\end{array}$ & Berhasil \\
\hline 5 & Jarak kamera & $\begin{array}{l}\text { Mengukur jarak } \\
\text { marker } \text { dengan } \\
\text { kamera }\end{array}$ & $\begin{array}{l}\text { Kamera dapat mendeteksi } \text { marker } \text { dengan jarak } \\
25 \text { cm }-100 \text { cm }\end{array}$ & Berhasil \\
\hline 6 & Warna marker & $\begin{array}{l}\text { Mengukur warna } \\
\text { marker }\end{array}$ & $\begin{array}{l}\text { Marker } \text { dapat terdeteksi dengan keadaan hitam } \\
\text { putim sampai sangat berwarna }\end{array}$ & Berhasil \\
\hline
\end{tabular}

\section{KESIMPULAN}

Berdasarkan penelitian yang telah dilakukan oleh peneliti tentang membuat aplikasi peta 3D Desa Muncan dengan augmented reality berbasis marker didapatkan kesimpulan bahwa aplikasi peta 3D Desa Muncan dengan memanfaatkan teknologi augmented reality berbasis marker sudah layak dan dapat digunakan untuk menyajikan batas wilayah, lokasi kepala dusun, sekolah, tempat ibadah, tempat-tempat perekonomian, wisata, budaya, kondisi geografis dan potensi di setiap dusun melalui kamera smartphone.

\section{REFERENCES}

[1] Mastur, "profil desa muncan 2017.” Pemerintah Desa Muncan, Lombok Tengah, p. 93, 2017.

[2] M. B. Azuma R, Baillot Y, Behringer R, Feiner S, Julier S, Recent Advances in Augmented Reality. IEEE Computer Graphics and Application, 2001.

[3] H. Abdurrahman and R. Asep, “Aplikasi Pinjaman Pembayaran secara Kredit pada Bank Yudha Bhakti,” J. Comput. dan Bisnis, vol. 8, pp. 61-69, 2014

[4] L. M. K. Khosim Amir, Geografi untuk SMA/MA Kelas XIII. Jakarta: PT Grasindo.

[5] A. Nugroho and B. A. Pramono, "Aplikasi Mobile Augmented Reality Berbasis Vuforia Dan Unity Pada Pengenalan Objek 3D Dengan Studi Kasus Gedung M Universitas Semarang," J. Transform., vol. 14, no. 2, p. 86, 2017, doi: $10.26623 /$ transformatika.v14i2.442.

[6] M. A. Arief, H. Wibawanto, and A. luhur Nastiti, Membuat Game Augmented Reality (AR) dengan Unity 3D, 1st ed. Yogyakarta: ANDI, 2019.

[7] M. Tjahyadi, A. Sinsuw, V. Tulenan, and S. Sentinuwo, "Prototipe Game Musik Bambu Menggunakan Engine Unity 3D," J. Tek. Inform., vol. 4, no. 2, pp. 1-6, 2015, doi: 10.35793/jti.4.2.2014.6990.

[8] R. Indriani, B. Sugiarto, and A. Purwanto, "Pembuatan Augmented Reality Tentang Pengenalan Hewan Untuk Anak Usia Dini 
Berbasis Android Menggunakan Metode Image Tracking Vuforia," Semin. Nas. Teknol. Inf. dan Multimed., pp. 73-78, 2016.

[9] P. Vazquez and F. Siddi, "Pengertian Blender," blender.org, 2021. .

[10] I. Binanto, Multimedia Dasar - Dasar Teori dan Pengembangannya. Yogyakarta. Yogyakarta: Penerbit Andi, 2010. 